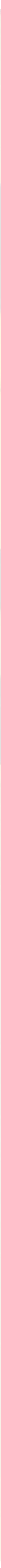




\title{
Mapping Bodies
}

\author{
EMMA MINKLEY \\ Centre for Humanities Research and Department of History, University of the Western \\ Cape
}

The images in the visual essay that follows this text are drawn from a set of partnered art events, the Museum of Truth and Reconciliation and Double Portrait/Haunting Objects. The latter took place at the University of the Western Cape in Cape Town, South Africa, in March 2018 as part of the programme at the workshop titled, 'Missing and Missed: The Subject, Politics and Memorialisation', and was intended to be read as a second chapter of the Museum of Truth and Reconciliation, which was enacted in Toronto, Canada in October 2016. The Toronto event invited participants to compile and collate objects collected from the streets of the city in response to a suite of cue cards containing pictorial and textual prompts on themes relating to truth and reconciliation, loss and memory. ${ }^{1}$ The collected objects, ranging from bits of organic matter to written pamphlets to foodstuffs, are now stored in small compartmentalised plastic 'collector's boxes' - each imbued with individualised notions of the given prompts. The cue cards exist as a set of indexical maps. Simultaneously images and objects, they hold information on routes through the city, as well as outlines of things and ideas, lost and found.

Using this seemingly disparate collection - a 'beta-museum' of material and aesthetic forms ${ }^{2}$ - the Cape Town event, Double Portrait/Haunting Objects, sought to reactivate the found objects in a new context and within an altered economy of value. This time, the objects, their accompanying cue cards and small storage boxes, were displayed in a darkened room alongside a set of overhead projectors. Participants were invited to interact with the objects, pictures and cue cards, using the projectors to create silhouetted images on multiple projected screens. Through this process, the objects took on a doubled meaning through their relationship with the Museum of Truth and Reconciliation, and were further multiplied in material and shadowed forms, both tangible and transient, absent and present - objects and images became shadows. The objects were made to occupy a second sphere of 'missingness' in the context of the workshop, which relocated them in a 'shadow world' in which spectral and haunting versions of their material and former selves were formed.

\footnotetext{
Photographs by Corinne Kratz (used with permission).

The textual prompts are listed at the beginning of the visual essay that accompanies this text. The prompts, textual and pictorial, were derived from various readings and images including: C. Barrette, B. Haylock and D. Mortimer (eds), Trauma Imprints: Performance Art, Literature and Theoretical Practice (Oxford: Inter-disciplinary Press, 2011); C. Lévi-Strauss, The Savage Mind (London: Weidenfeld and Nicolson, 1966); M. B. Hansen, Cinema and Experience: Siegfried Kracauer, Walter Benjamin, and Theodor W. Adorno (Berkeley, CA: University of California Press, 2012); Fluxkits by the late-twentieth-century Fluxus art movement; the 1997 theatrical production Ubu and the Truth Commission by William Kentridge, Jane Taylor and the Handspring Puppet Company; Jillian Edelstein's photographic series in J. Edelstein, Truth and Lies (London: Granta, 2001); and Patricio Guzmán's 2015 film, The Pearl Button. Further visual links can be made with Marlene Dumas' ink drawings of bodies and fragments of bodies in Models (1994) or her Magdalena series (1996), as well as with the interactive and tactile aspects of Sue Williamson's Truth Games (1998).

2 I use the term beta-museum to convey the sense in which the collection is unofficial and uninstitutional in that it is made up of a secondary layer of seemingly 'unimportant' objects.
} 
Their doubling through projected forms was further complicated by the inclusion of the bodies, particularly the hands, of participants themselves in silhouetted form. Thus, the subject, whether participant or found object, was doubled, othered and fragmented.

The emphasis on collection and collation stirs up an awareness of 'missing' objects - less in the sense of being lost, and more as objects that are discarded, thrown away or left behind. In the context of the two art events, 'missingness' first appears through a connection to a missing object, rather than a missing subject, who is figured only later via a series of the former. The fragmentation evident in the projected images and collected objects speaks to the notion that, in fact, objects or 'things' can present more convincing evidence of the human (or of the subject) than the human body itself. ${ }^{3}$ The phrase 'Double Portrait', in the title of the Cape Town event refers to the ways in which objects such as puppets or photographs can become doubles or portraits of the self. Through such objects, the human body is rendered absent but present, whole but segmented.

Both art events worked to activate the sense of touch, particularly by and of the hand, unearthing a link to forensic investigation and the documentation of objects, referencing human bodies in terms of found physical evidence of the location or situation of those who are missing. Interestingly, touch can be partly objective and partly subjective. As Jan Švankmajer asserts, 'While touching, we project a sensation outwardly, outside of us; at the same time we perceive it subjectively, on our skin.4 This means that 'touch can play an important role in overcoming the opposition of object-subject.' ${ }^{5}$ In this way, a practice or methodology of 'missingness' was outlined at these events through a mimicking, in very basic form, of the processes involved in exhumation, forensic investigation, as well as archaeological and museological practices involved in the archiving and display of the human body. The gathering and display of objects, via both events, shadowed the process of finding and locating meaning (and bias) in objects that serve as extensions, prostheses or apparatuses of the hand.

Hands, too, can be 'organs of perception, weapons of attack and defence, means of communication.' ${ }^{\prime}$ The hand 'has an extremely long history both as an implement of social interaction and as the object of social attention." The hand comforts, it cares, but it also manipulates and oppresses, as is evident in the hand which/who creates missing subjects, the hand of the perpetrator or agent of violence. A hand can turn into a cup, a vessel to nourish, a blank screen or a surface, and, with its dextrous fingers and opposable thumbs, it can transform into a multitude of tools for holding, grasping, pressing, turning. Hands can be 'monsters, for their insatiable craving, their curiosity, subverts any order. Within the order of things, hands are in fact agents of provocation and subversion. They have infiltrated nature to subvert it, and,

See N. Rousseau, 'Eastern Cape Bloodlines I: Assembling the Human', Parallax, 79, April-June 2016, $203-218$.

J. Švankmajer, Touching and Imagining: An Introduction to Tactile Art (London and New York: IB Tauris, 2014$), 2$.

Švankmajer, Touching and Imagining, 2.

V. Flusser, Gestures, 1991, trans. N. A. Roth, (Minneapolis, MN, and London: University of Minnesota Press, 2014 ), 34.

F. R. Wilson, The Hand (New York: Vintage Books, 1999), 147. 


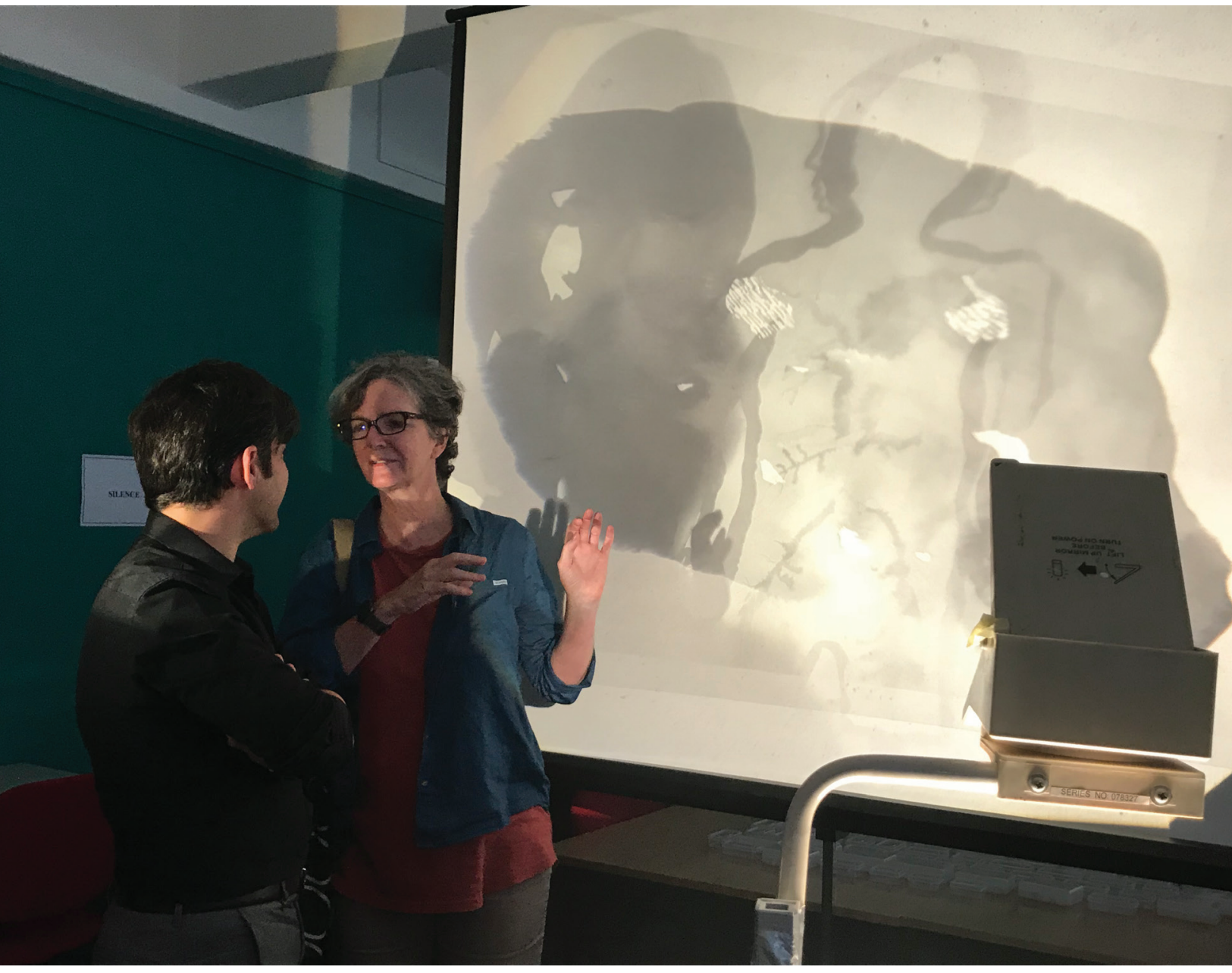

being unnatural, they become unsettling, even repulsive.' For Jacques Derrida (via Heidegger), 'The hand will be the (monstrous) sign [le monstre], the proper of man as (monstrous) sign.9 Vilém Flusser claims that our hands determine our mode of being in the world; the fact that we approach life dialectically, from 'two opposing sides' - 'a good and a bad, a beautiful and an ugly, a bright and a dark, right and a left.' ${ }^{10}$ This mode of being and doing allows the world to be 'be taken in, grasped, intended, and manipulated.'11 The hand can thus stand as a metonym for care and comfort but conversely also for violence or manipulation.

8 Flusser, Gestures, 34.

9 J. Derrida, 'Geschlecht II: Heidegger's Hand' in J. Sallis (ed.), Deconstruction and Philosophy: The Texts of Jacques Derrida (Chicago, IL: University of Chicago Press, 1989), 168.

10 Flusser, Gestures, 33.

11 Flusser, Gestures, 33. 


\author{
Appearing/Vanishing \\ Monument to Lost People \\ Mapping Bodies \\ Moments/Monuments \\ Flotsam and Jetsam \\ Lost and Found \\ Placed/Displaced \\ Empty Shells \\ Replaced and Re-placed \\ Petrification and Mortification \\ Body Fragments \\ Burying/Covering \\ Remembering and Re-membering \\ Trauma Imprints \\ Detritus \\ Debris \\ Souvenir
}




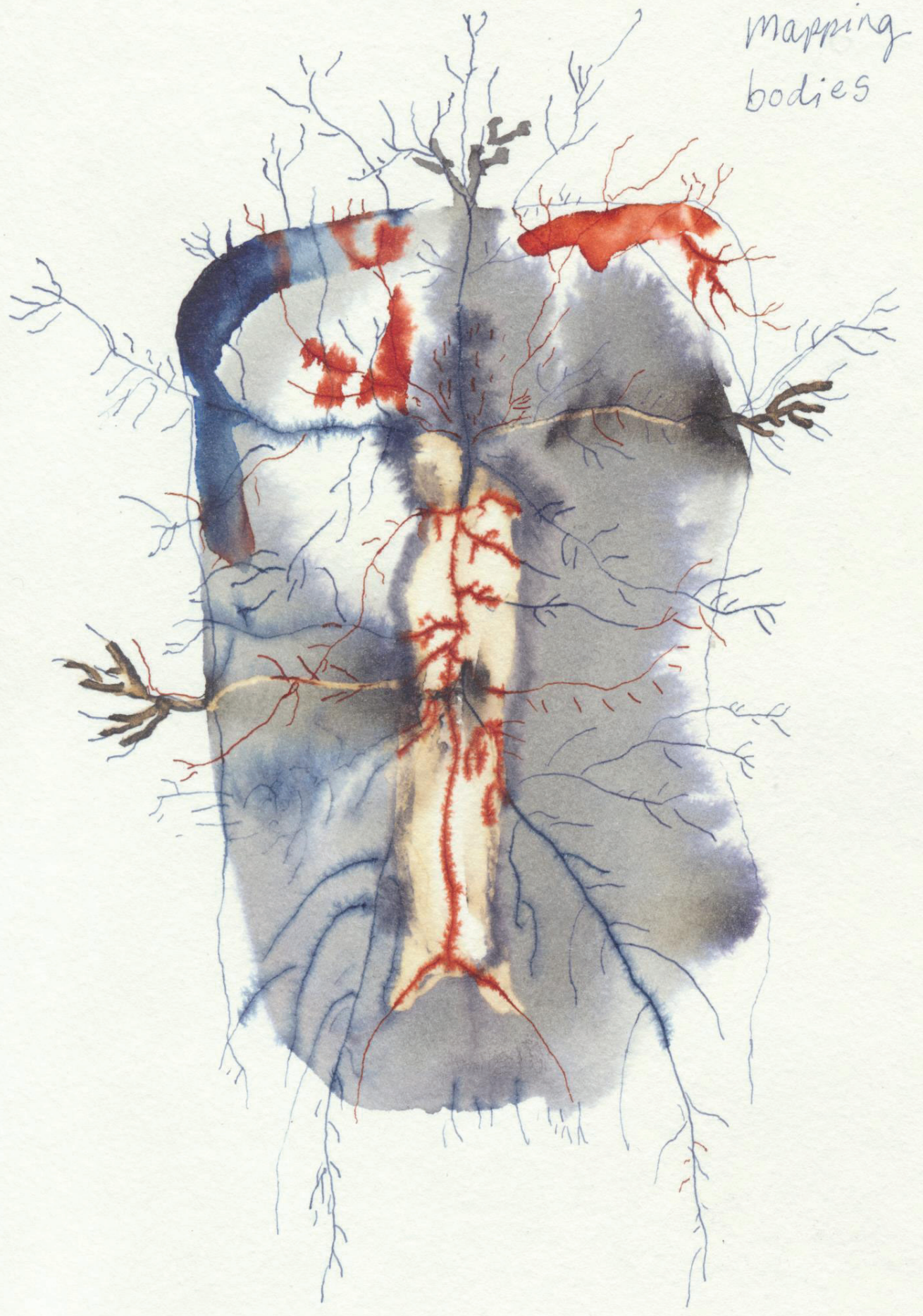




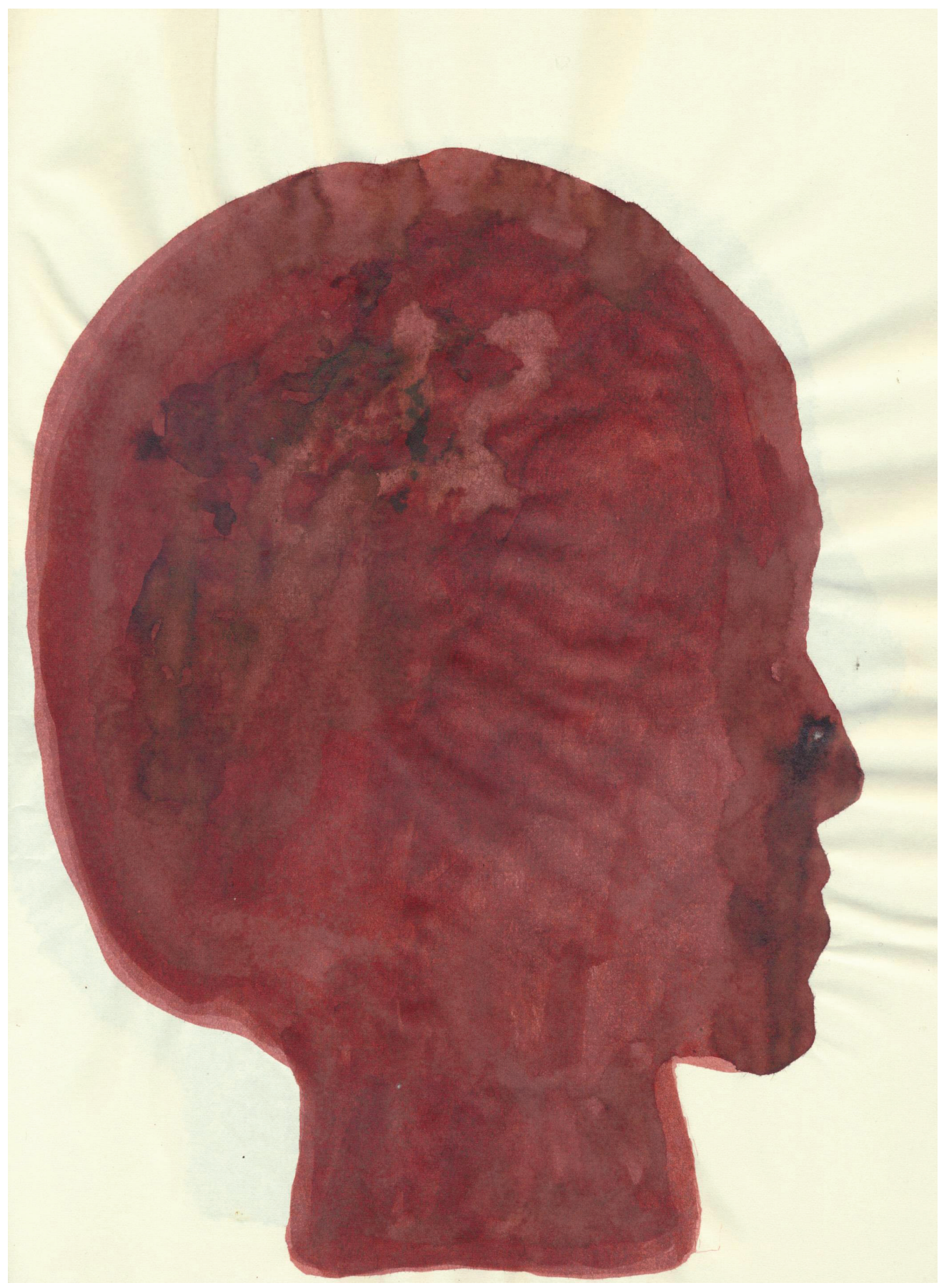




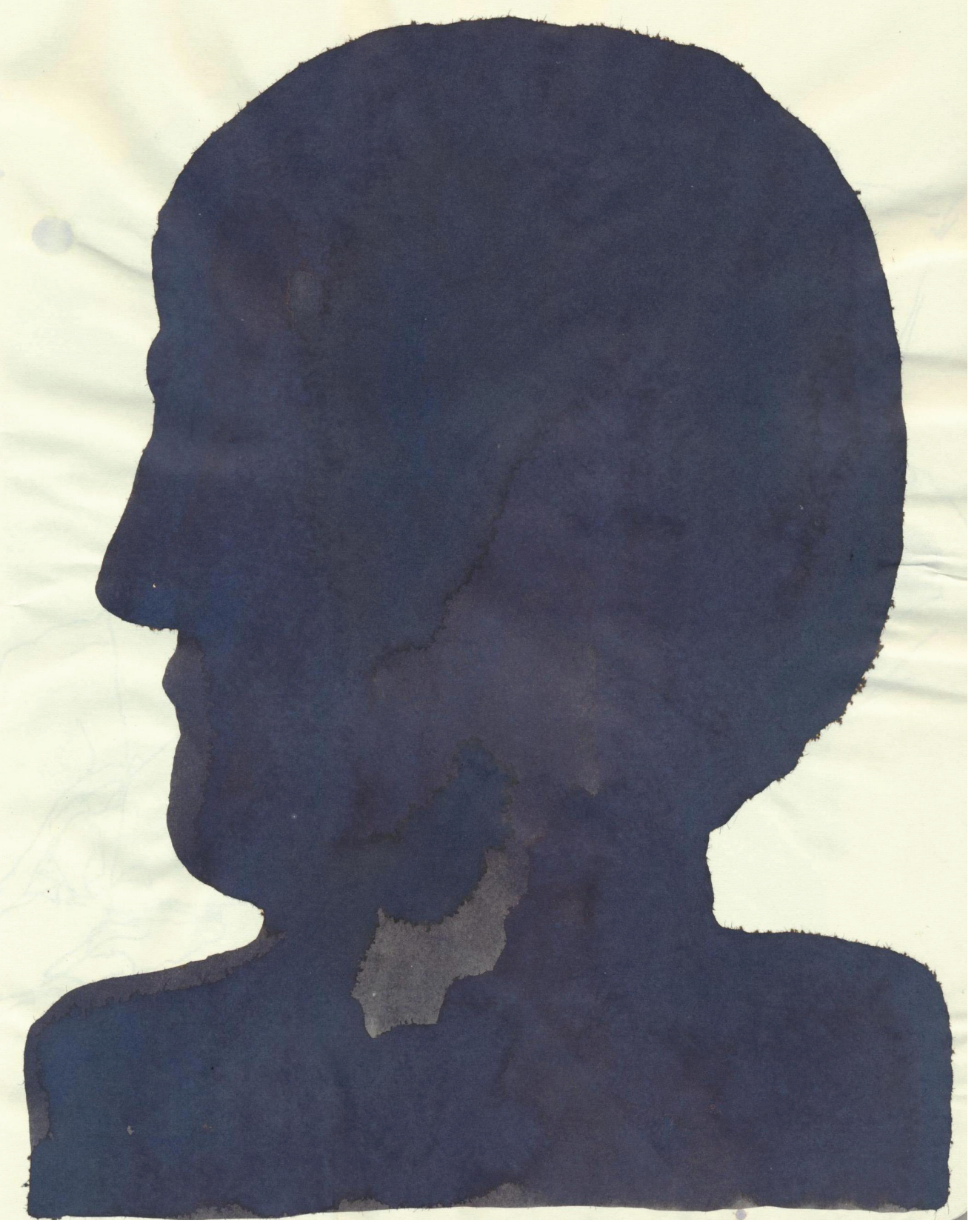




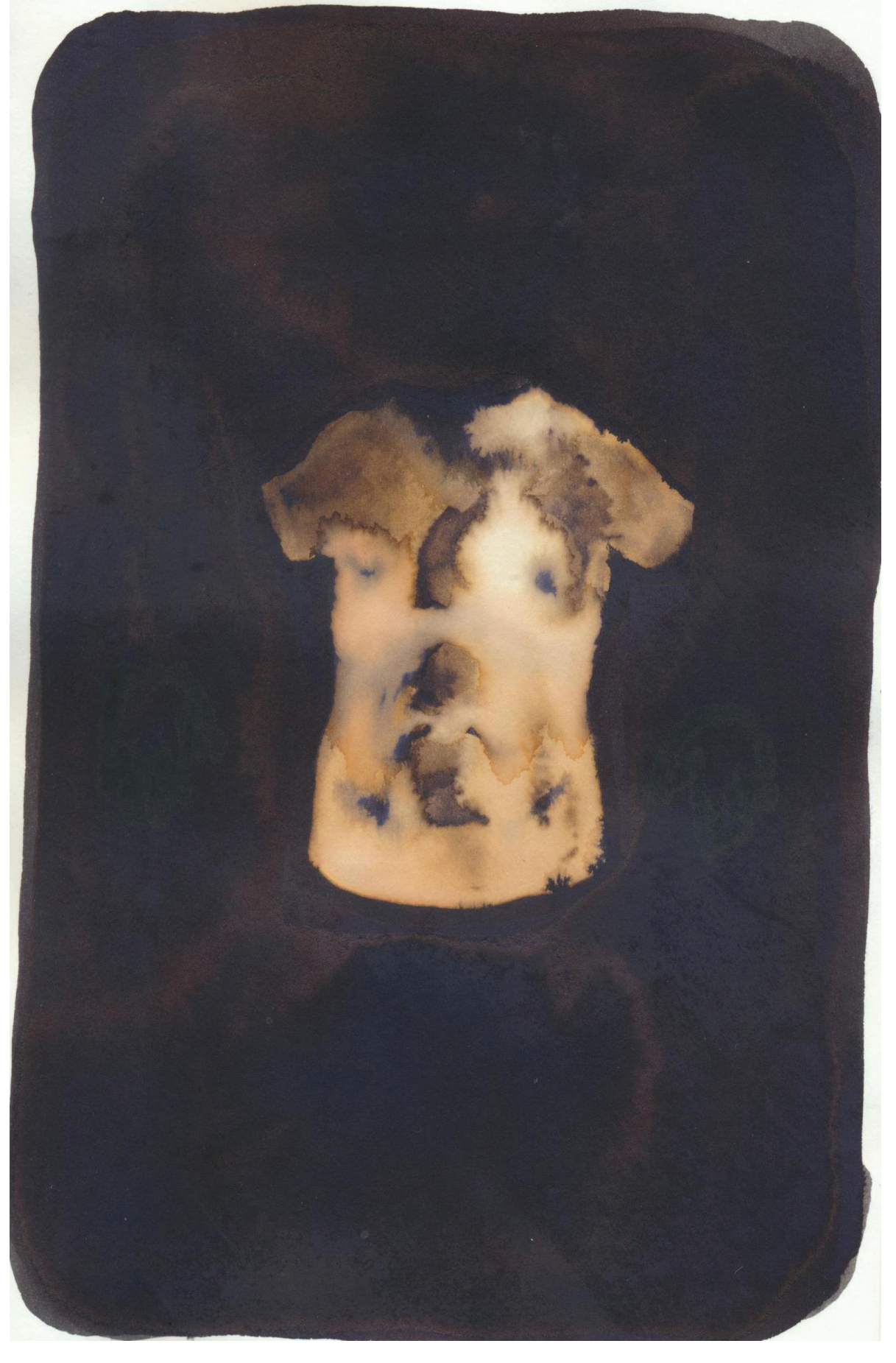




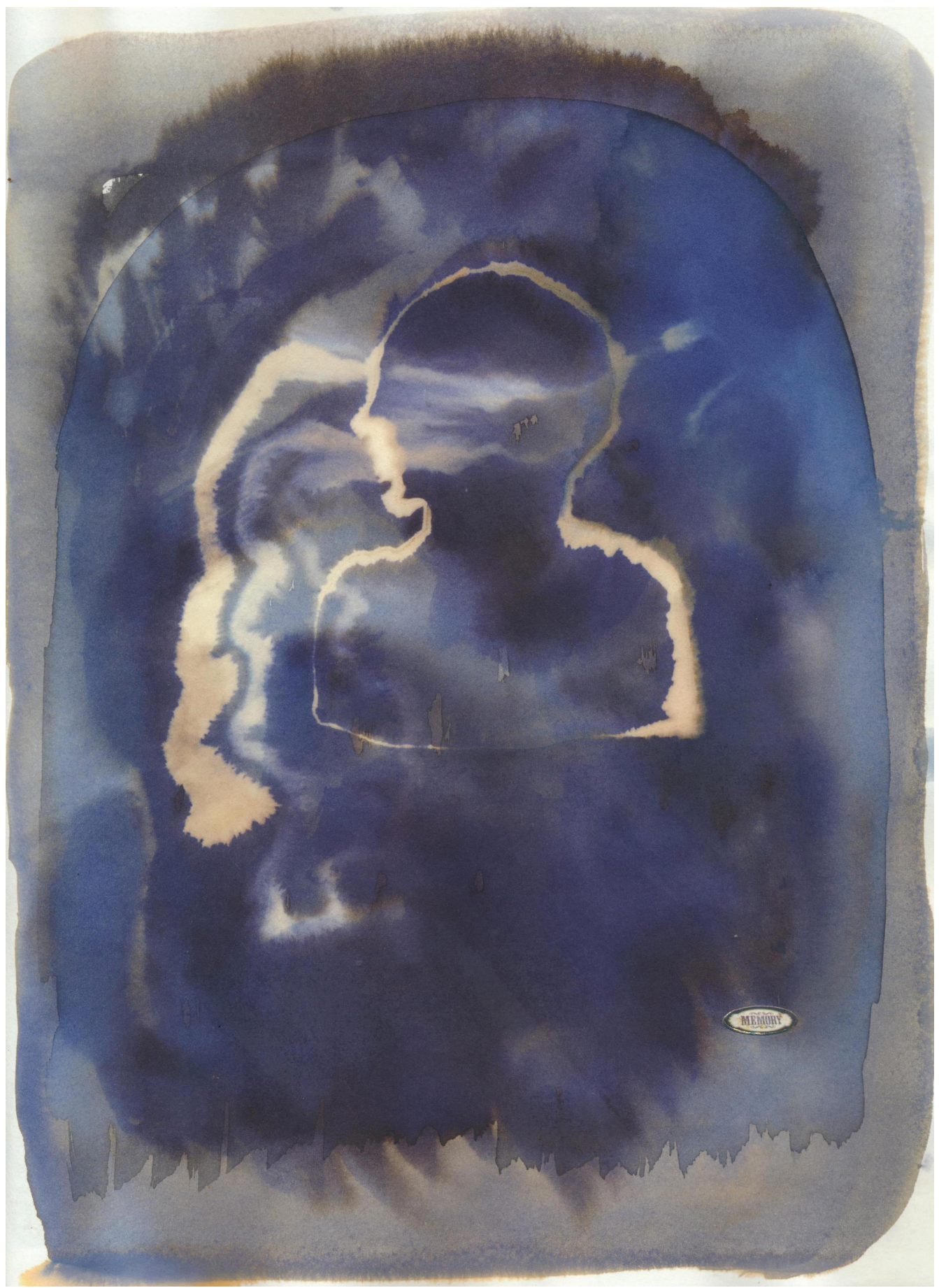




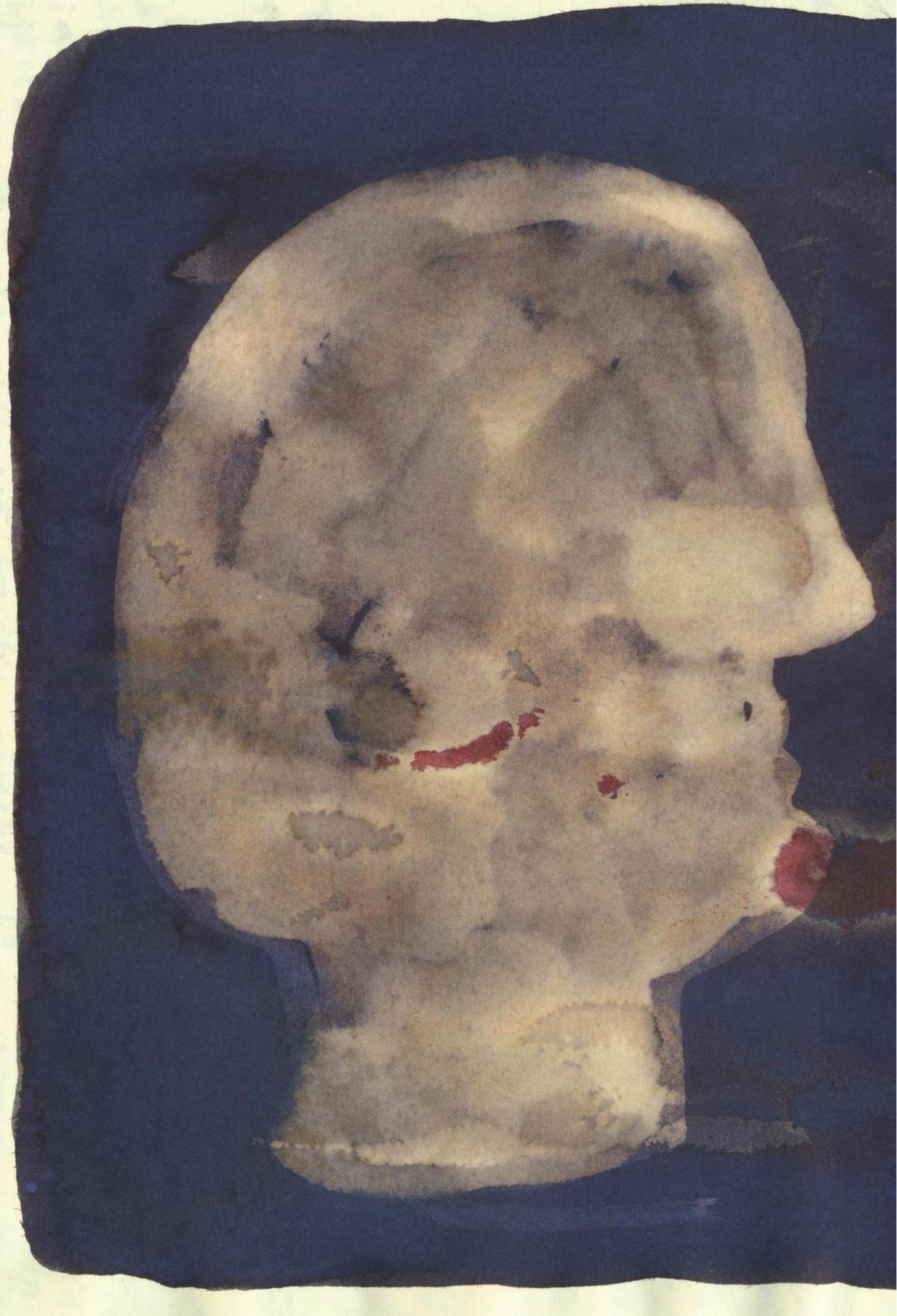




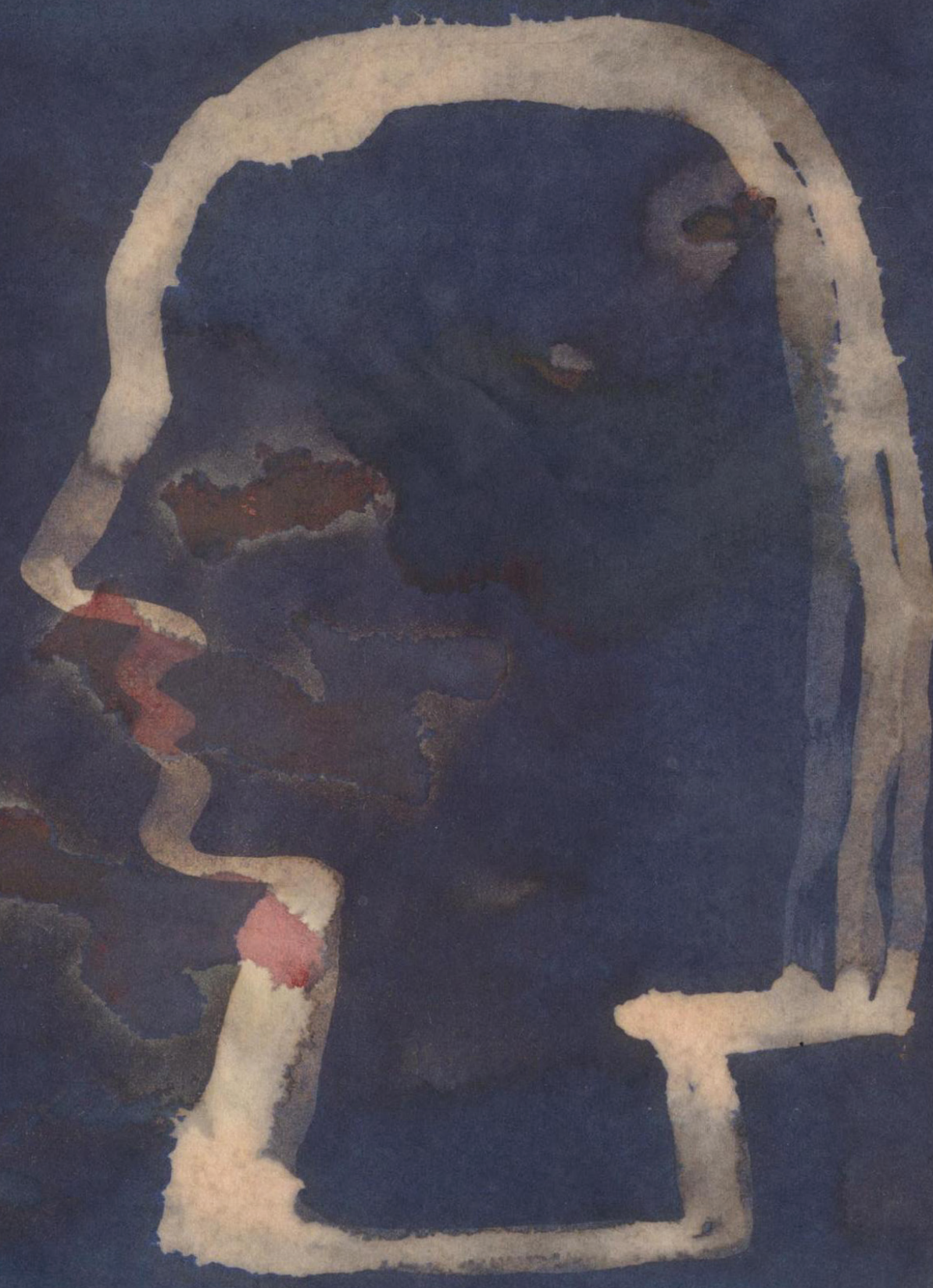




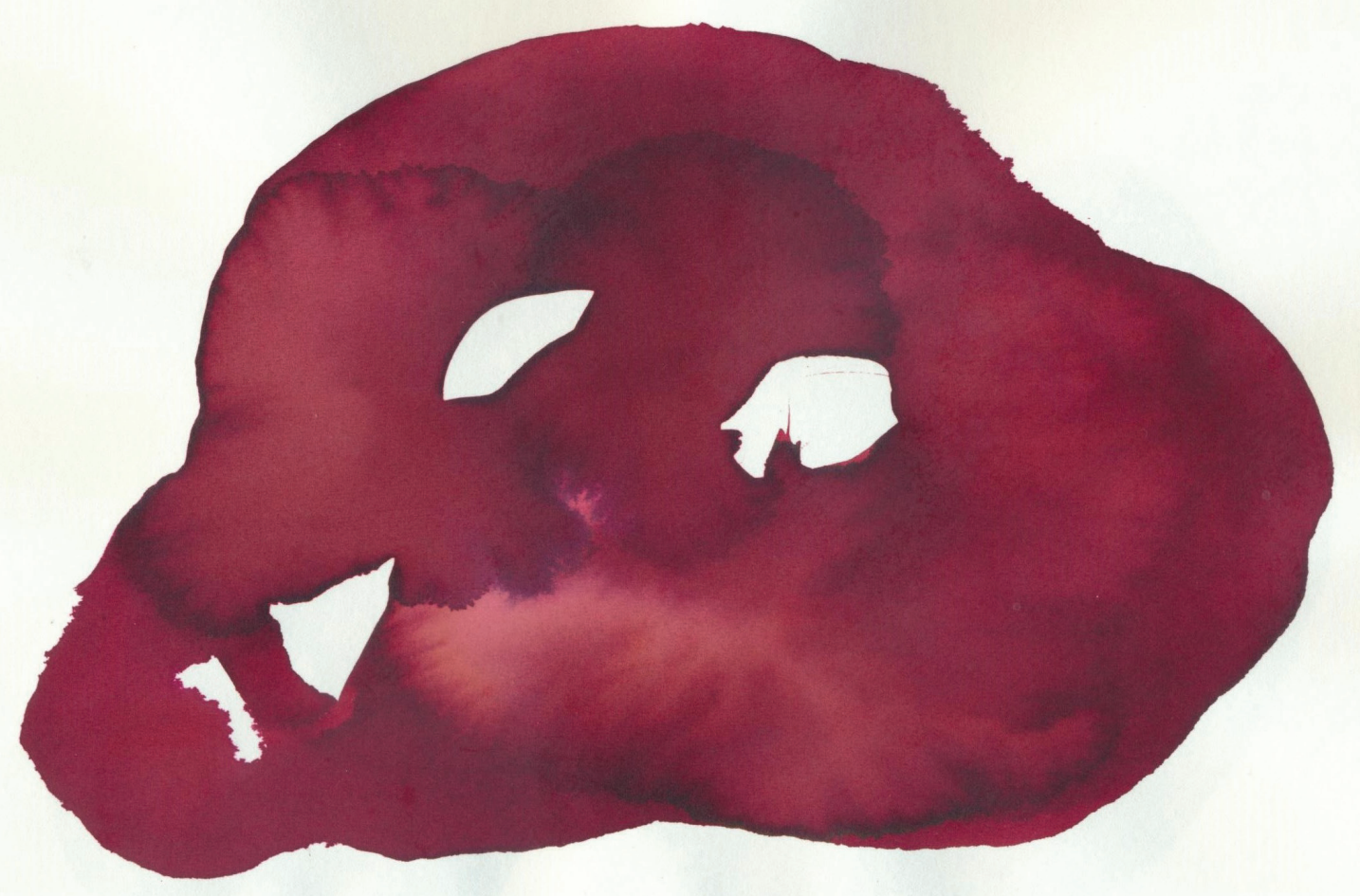





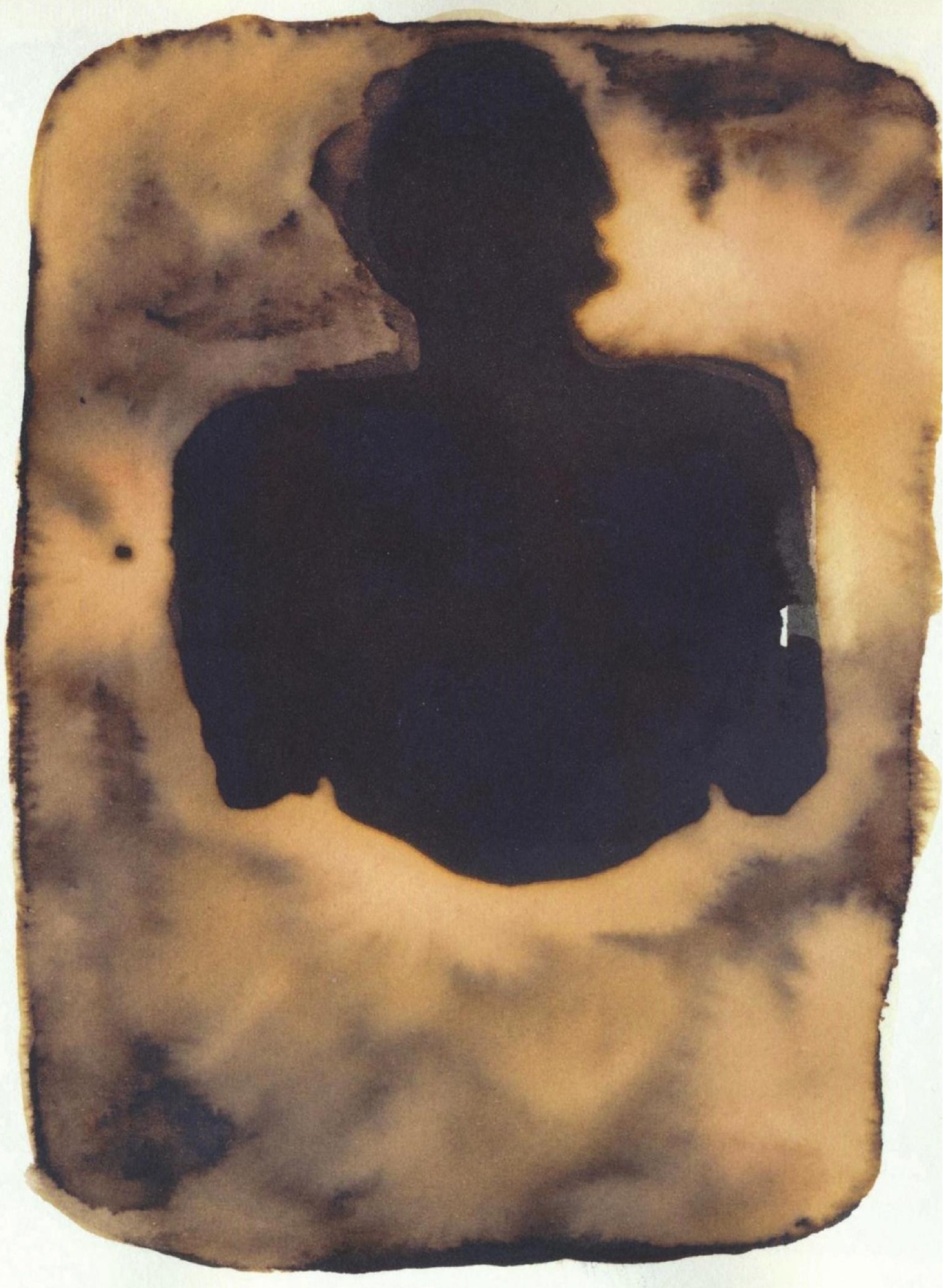




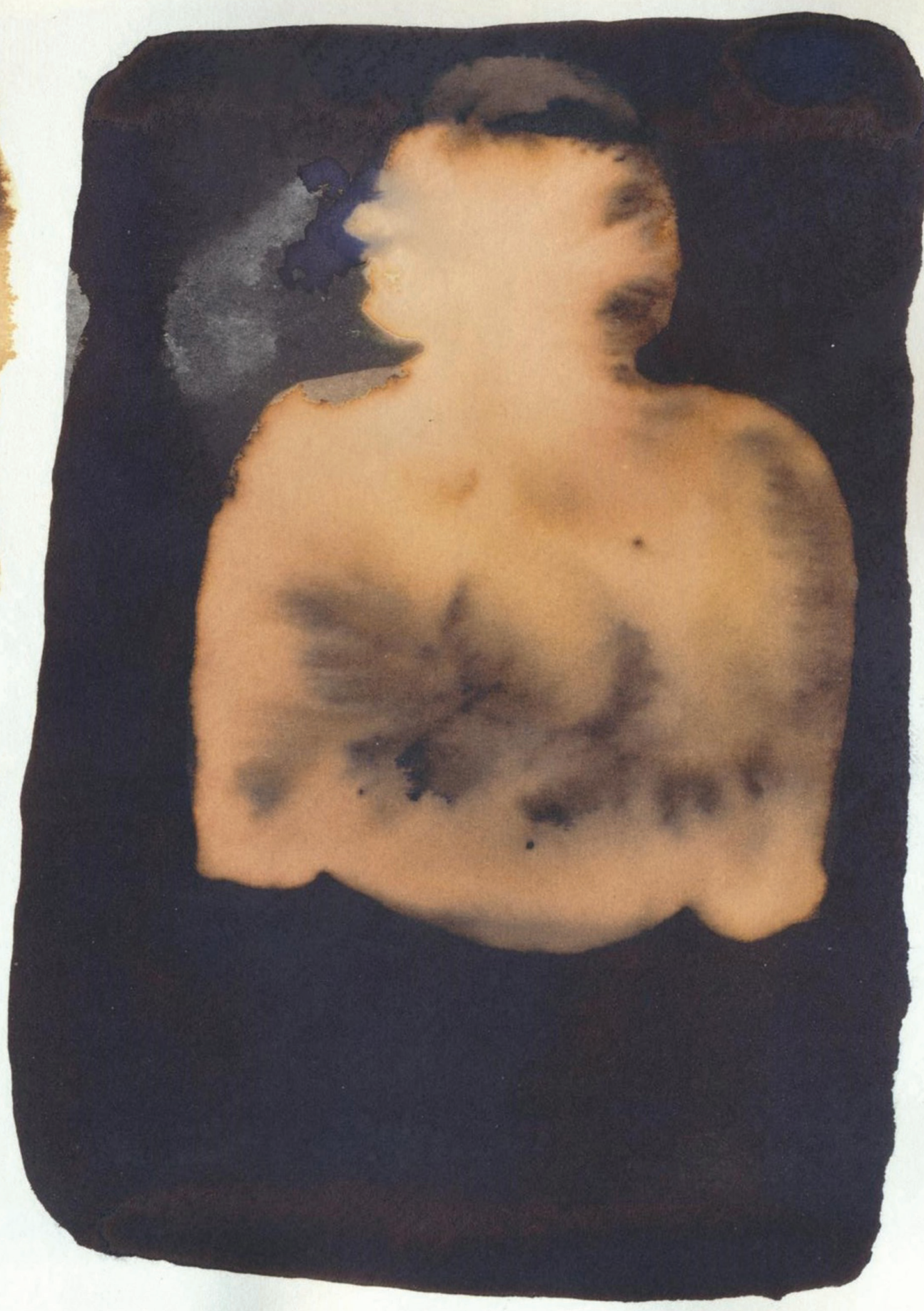

